\title{
A study on benefits of using illustrations (pictures, real object, etc.) in learning English vocabulary of non-English major stu- dents at Ho Chi Minh City University of Food Industry (HUFI)
}

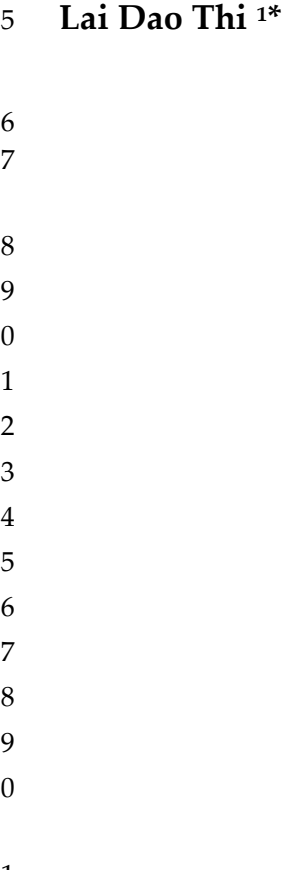

Citation: Dao Thi, Lai. (August 17, 2021) A study on benefits of using

illustrations (pictures, real object, etc. ) in learning English vocabulary of non-English major students at Ho Chi Minh City University of Food Industry (HUFI)

https://osf.io/2dfwu/

Academic Editor: Lai Dao Thi

Received: August 17, 2021

Accepted: August 17, 2021

Published: August 17, 2021

Publisher's Note: MDPI stays neur4 tral with regard to jurisdictional ${ }_{5}$ claims in published maps and institutional affiliations.

\author{
1 Ho Chi Minh City University of Food Industry; daothikhanhbang@gmail.com \\ * Correspondence: daothikhanhbang@gmail.com ; Tel.: +84 333734309
}

\begin{abstract}
Learning vocabulary is an important element of foreign language learning, since the meaning of new terms is emphasized often in books and classrooms. It is an important part of language learning. It is also essential in language education and for language students. Research recently shows that it is difficult to learn vocabulary. The most popular methods of learning and teaching in language classrooms around the world have been proposed by researchers, in which the use of illustrations is highly appreciated by them. Illustrations play an important role in teaching and learning vocabulary of the language. Images connect students and previous knowledge with a new story, thereby helping them learn new words. A word can be described with an illustration and an illustration can contain many words. The main objective of this study was to study the benefits of using illustrations (pictures) to help non-English majors at HUFI learn English vocabulary. Evaluation and analysis are the most important ways to make research more authentic. The findings show that the usage of illustrations has a lot of benefits to students' vocabulary learning.
\end{abstract}

Keywords: illustration, teaching, non-English majors, learn English vocabulary.

\section{Introduction}

Communication is part of human nature. Words are one of the main components of communication. Starting with a language requires a large vocabulary. However, each different context is constructed with separate words. In the fact that opportunity's acquisition, distribution, and interaction are limited for target language in a communicative context. The motivation and effective learning strategies are seemly required for learning vocabulary (Tseng, 2008, Phuc et al., 2019). The picture is one of the variability of teaching supports which is used to describe language meaning structure, to employ learners in a topic, or as the base of an entire activity (Harmer, 2001). Acquiring vocabulary is very important whether learning the first, second or any foreign language (DeCarrico, 2001). Using pictures in combination with reading vocabulary is a simple way to make a deep impression and increase students' memorization ability. Using a variation of media will increase the chance that the learners will recall better what they learn in developing the performance of skills, expected to improve. A picture is one of the many types of teaching media that can be used to deliver the lesson (Brown, 2004).

\section{Literature Review}

\subsection{Teaching vocabulary}

2.1.1. General concept of teaching 
Teaching is primarily a social activity, implying a role relationship between the teacher and the learners, as well as learners and learners (Wright \& Tony, 1987). Teaching may be defined as showing or assisting someone in learning how to do something, providing guidance, helping guide someone in the study of something, providing knowledge, causing someone to know or understand something (Brown, 2000).

The improved quality of the students depends on how the educator imparts them. Data exists as explicit information. Each teacher needs to provide himself with a rich database to meet the needs of the learners.

\subsubsection{General concept of vocabulary}

To understand language, learners must master vocabulary. Vocabulary as a part of language is one of the basic information that contributes significantly to the completion of writing, speaking, reading, and writing skills. Vocabulary learning is an essential part of learning a language because the meaning of new words is often emphasized, whether in books or the classroom. It is also central to language instruction and is of importance to language learners.

New language learners typically consider vocabulary knowledge to be a vital skill since a restricted vocabulary might hamper successful communication. Emphasizing the importance of vocabulary acquisition, Schmitt (2000) emphasizes that vocabulary knowledge is vital to correspondence abilities and to secure a subsequent language.

According to Hornby in the oxford advanced learner's dictionary of current English, it is expressed that vocabulary is the complete number of words in a language, all words known to an individual or utilized in a specific book, subject, and so on ( (Hornby, 1995). The vocabulary is also known as the knowledge of words and meanings. More specifically, the writer uses vocabulary to refer to the types of words that students must know in order to read increasingly difficult text with comprehension (Kamil \& Hiebert, 2005).

There are two forms of vocabulary, active and passive. A student's "taught" vocabulary is the first sort of vocabulary they should be able to use. The passive vocabulary refers to terms that students will know without pronouncing when they see them (Harmer, 1991).

\subsubsection{Teaching vocabulary}

Teaching vocabulary is an important aspect of learning a language because vocabulary is a language's basic building component (Alqahtani, 2005). Vocabulary is an essential part of every language. For Vietnamese speakers, teaching English as a foreign language can be challenging. Teachers are required to bring the new language closer to the learners' ears. Students' requirements and preferred learning methods are best understood by teachers, who may then create resources that assist students to overcome obstacles to learning English and enhance their English abilities more readily (Son \& Nghi, 2019). Effective teaching is a fundamental factor leading to the success of the teaching-learning process. To prepare for effective teaching, teachers need to come up with a theory to explain effective teaching. Therefore, it is important to develop principles of preparation for language teachers, especially vocabulary teaching.

\subsubsection{The importance of teaching vocabulary}

Vocabulary is central to language and essential for the average language learner (Coady \& Huckin, 1997). Following Lewis (1993), they do not travel with grammar books, but rather with dictionaries.

No matter how well students learn grammar or master the sounds of a foreign language (L2), communication in L2 cannot take place in any meaningful way unless they have words to communicate a larger variety of meaning (McCarthy, 1990).

All aspects of language start with words. Choosing the right language requires communicators to have a rich vocabulary and know how to use them, to suit all situations. Oxford (1990) also states that the vocabulary is, because of the tens of thousands of different 
meanings, this is by far the most significant and unmanageable component of learning any language, whether a foreign or one's native language.

\subsubsection{Teaching and learning English vocabulary in non-English major students at HUFI}

During the integration period, English majors are no longer restricted by other majors. In the present day, foreign languages, especially English which used by all occupations as both a tool and a talent. More and more students are learning English as an effective tool in their current field or for their future careers. It also provides possibilities to work overseas or to receive prizes in other countries. It means that today's learners need to become more proficient in English, which is no longer only a foreign language.

Responding to that urgent need, HUFI has also equipped students with an English learning environment that current goal of schools. Due to the specificity of being a non-specialized language school, most of the students are in remote provinces, so their English is limited qualifications. Therefore, when approaching specialized English, there are many difficulties, especially in terms of vocabulary.

As mentioned above, vocabulary is a system of words that make up a language. To have perfect communication, it is necessary to develop a suitable study plan. However, sometimes you face problems in completing it. Here are some typical reasons: Firstly, most students with diverse subject backgrounds have to learn a large amount of English vocabulary at the same time, to ensure completion of all subjects on time term. Secondly, they choose to learn each word separately - write each word, learn each meaning. And finally, they lack the motivation to learn. So, texts and illustrations familiar to the learners' cultures should be used to assist them to overcome this obstacle (Son \& Nghi, 2019).

\subsection{Illustration}

\subsubsection{General concept of illustration}

Illustrations are an essential element in any language course book. Illustrations are a common language in sequence with the visual world's requirements. Human beings' first language is the image (Olshansky, 2008). It offers a means that we can understand intuitively. Illustrations are excellent teaching aids in today's "visual world" since they present to the eye what can only be imagined otherwise (Houghton \& Willows, 1987, Nghi, 2020). Beginning very long ago, people had spoken with visual components, paying little heed to their imaginative quality (Domin, 2007). Paintings helped storytellers by providing a supporting role to what they told in ancient times, and in similar forms, in particular, illustrations became part of printed material such as storybooks in modern times (Carney \& Levin, 2002). In addition to storybooks used primarily for young students, textbooks designed for students in most grades starting from kindergarten through graduate school also have illustrations.

The sense of vocabulary objects can be explained using pictures. Virginia French says that a picture is useful to help students understand the significance of a word (Allen, 1983). Using illustration in teaching English vocabulary:

*Warm up

Warm-up is the first step in the teaching process. During this step, the teacher presents the new materials to the students. The teacher will ask a few questions related to the material or topic discussed.

For example, if the topic is about the weather, the teacher will ask students some questions as follows:

How is the weather today?

What happens if the sky falls?

Vietnam's weather has several seasons?

This activity is designed to introduce a new topic to students.

*Presentation 
In the second activity, the teacher begins to explain the materials to the listener. In learning English, there are four skills: listening, speaking, writing and reading, which you must be proficient. In this step, the teacher can use several teaching facilities to help them explain the material easily.

In teaching listening using pictures, the teacher comes up with it by asking students to listen and then repeat it. For example, when the subject is climate, the teachers give little pictures of downpour, sun, and mention their names and afterwards the learner needs to repeat those things. Pictures of vehicles and their names referenced. In this ability, the teacher will make energy for students in learning.

In speaking, the teacher leads the student to the next activity. For example, she would post a picture and ask about other activities. This activity can get students to understand objects and help them say the correct names of objects.

In reading teaching, during the time spent exploring the vocabulary, the teacher will let the students repeat it over and over so that they pronounce it well.

In writing teaching, when teaching with pictures, students have to explain vocabulary. Then rewrite words based on that image.

2.2.2. Advantage of using illustration in teaching English vocabulary

According to Gerlach and Ely (1980), there are advantages of the pictures as follows:

- Pictures are cheap and widely accessible.

- For a whole community they give common experiences.

- The visual detail enables the study of subjects that would otherwise be impossible.

- Misconceptions can be avoided and corrected with the help of images.

- Images stimulate further study, reading, and research. Visual evidence is an extremely effective tool.

- They aid in the development of critical judgment and the concentration of attention.

- It is easy to manipulate.

The use of illustrations has contributed to attracting the students' attention. Visuals are useful to focus students' attention on the lesson, helping them visualize vocabulary. When students are attracted to images, they pay more attention to learning. Images have an important function as a learning aid simply because they attract students' attention and help encourage them to focus on one subject.

It is important to make sure that the images are not ambiguous. Using images is an attempt to help students to understand and absorb something clearly and easily. However, teaching using pictures has an important role to play in understanding meaning. It is mean that the usage of images has an impact on the memory of vocabulary learning.

\section{Materials and Methods}

This study aims to investigate the significance and ability to memorize words while looking at specific images. As a result, the quantitative study design has chosen because it has allowed for the evaluation of the benefit of illustrations in learning English vocabulary. Assess the impact in objective questions of illustrations on vocabulary research.

\subsection{Participants}

The sample consisted of 150 participants of 150 students who were randomly selected out of 10,000 students at HUFI. In particular, there were 98 females and 52 males, according to which freshman, 2nd year, 3rd and 4th-year students respectively account for $4 \%, 8 \%, 66 \%$ and $22 \%$.

A content analysis was described as a research approach for drawing repeatable and valid inferences from texts (or other meaningful matter) to the contexts of their usage (Krippendorff, 2004). It used a range of approaches, which were employed to draw valid inferences from the text (Weber, 1990). 
Table 1 Sample sizes according to gender

\begin{tabular}{cccccc}
\hline School year & Freshman & Sophomore & Junior & Senior & \\
\hline Sample size & 6 & 12 & 99 & 33 & $\mathbf{1 5 0}$ \\
\hline
\end{tabular}

\subsection{Instrumentation}

To assess the effect of pictures in learning English language, the instruments used in this study are a vocabulary exam and a checklist. In the trial, the vocabulary test consisted of 5 random photos with current user-friendliness. Such an examination aims to test the ability to record images with words. In research, another tool is used as an article type of the image level in the phrase. This includes 12 options for questioning. The assessment is used as a follow-up test.

\section{Discussion}

4.1. The gender impacts the time on English learning of non-English major students at HUFI

Table 2 The gender impacts the time on English learning

\begin{tabular}{lccccc}
\hline \multirow{2}{*}{ Gender } & Sample size & \multicolumn{4}{c}{ The time on English learning } \\
\cline { 3 - 6 } & & $<30 \mathrm{~m}$ & $1 \mathrm{~h}$ & $2 \mathrm{~h}$ & $>2 \mathrm{~h}$ \\
Male & 52 & 18 & 28 & 3 & 3 \\
Female & 98 & 20 & 32 & 20 & 26 \\
\hline
\end{tabular}

Table 3 Sample sizes according to level of excitement in learning English in gender

\begin{tabular}{cccc}
\hline Gender & Like & Dislike & Exciting \\
\hline Male & 25 & 28 & 10 \\
Female & 42 & 20 & 25 \\
Total & 67 & 48 & 35 \\
\hline
\end{tabular}

In the survey, it found that the percentage of male and female students who spent time learning English had a clear difference. Of the 150 participants, there were 52 $(34.67 \%)$ male students and 98 (65.33\%) female students. About the time to learn English, survey at 4 levels: less than 30 minutes, 1 hour, 2 hours and more than 2 hours. From the above data, gender had a significant influence on the amount of time it takes to learn English. In fact, each gender had a different way of enclitic (learning) language. In particular, with a second language (English), learners would show gender differences in learning styles. In different communication situations or different communication situations, must have words phrases, sentences, or different figurative languages.

Table 2 ( question 2 \& 6) showed that 18 students (34.5\%) out of 52 males spend less than 30 minutes learning English, while only about 3 students (5.8\%) spend more than 2 hours doing so. Meanwhile, approximately $20.4 \%$ of females spend 30 minutes studying and focus primarily on other times more, for example, 32 students (32.7\%) for 1 hour of study, 20 students (20.4\%) for 2 hours of study, and more than 26 students (26.5\%) for 
more than 2 hours of study. This disparity was caused in part by differences in learning styles. According to research, $60 \%$ of learning styles were genetically determined. Sex hormones had an impact on the way people behave. Furthermore, they believed that the right hemisphere of the brain is more developed in males.

Besides, there was a clear difference in the level of excitement in learning English in Table 3 (question 2 \& 5). The rate of interest in learning English was approximately 23.3\% (35sts), with females nearly twice as likely as males, but the rate of dislike had shifted: males are 1.4 times more likely than females (male: 28 , female: 20 ). Teachers could better understand the status of their students and apply appropriate teaching methods as a result of this.

\subsection{The importance of learning English vocabulary of non-English major students at HUFI}

Figure 1 Find the meaning of learning English vocabulary

\section{Do you think vocabulary is important in learning English?}

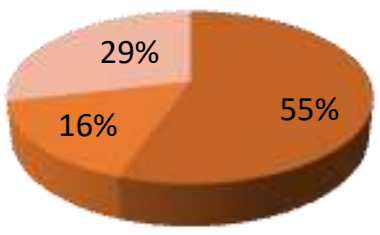

Figure 1 (question 6) was the result of the level assessment question. With the question, "Do you think vocabulary is important in learning English? ". About $16 \%$ of students believed that learning English was unimportant. According to the preceding statements, vocabulary was a tool for helping you understand the messages that must be conveyed when communicating. Did you know that in a conversation, neither party pays attention to grammatical structures, whether the other person was speaking in the correct English tense, and so on? Above all, engaging in an English conversation would boost your confidence and the meaning of your sentences.

\subsection{Difficulties in learning English vocabulary of non-English major students at HUFI}

Figure 2 Summary sample sizes according to difficulties in learning English vocabulary

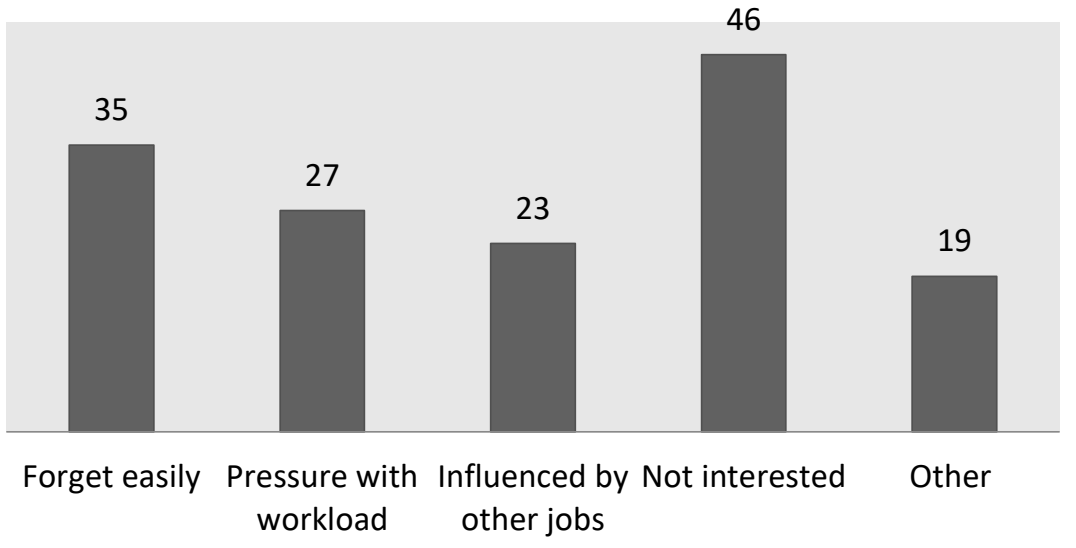


The survey summarized the five most significant limitations in figure 2 (question 8) which HUFI's students face when learning English by asking open-ended questions:

First, forget easily, which accounted for $35 \%$ of the survey samples. This was a very common mistake for most of you when learning English, and you were most likely no stranger to it. Evidence for this could be found in school, where at the end of each lesson there was usually a list of vocabulary words that students needed to remember. And you frequently tried to memorize numerous of these words, but after about a week, you almost forgot them.

Second, pressure with workload. You had learned a lot of vocabulary but only remember a few words after a while. The reason was not that you did not review, but that you studied incorrectly. Although English has contained approximately 20,000 words, only 3000 of the most commonly has used daily. Too many unnecessary words would waste time and made you not wanted to see them every day.

Third, influenced by other jobs. Other jobs had impacted 23 students in the survey sample. Almost all students, especially third and fourth-year students, who has worked part-time to spent or paid tuition fees, homework in specialized subjects, participated in classes or group activities, and so on. They were barely meeting the deadline for completing the work, and they were gradually becoming more stressed.

Fourth, no interested. This response was provided by as many as 46 samples. Learning vocabulary in a dry manner and sitting for hours to write words bores students. Furthermore, a lack of interest caused tasks to pile up that was making it difficult to complete them all.

Finally, 19 samples discuss other limitations in learning English vocabulary, such as general teaching and learning programs, weak students, difficulty to absorb, no learning goals, practice specific, focus on learning English, etc.

\subsection{Benefits of using pictures in learning English vocabulary of non-English major students at HUFI}

Some of the benefits offered by the participants in the survey samples of students at HUFI (question 12), via a related numerical questionnaire, include:

\subsubsection{To improve student motivation}

The increase in students' vocabulary was significant. When the students have seen the pictures, their English motivation would be improved. The students eagerly had taken part in the lesson, which had included answering questions and responding to the teacher's explanations. Then, high motivation aided in the improvement of students' vocabulary.

\subsubsection{To get students' attention}

Pictures could help students focus their attention on "What did the text say?" by allowing them to visualize it. In this way, students would rely on the images and the context which be attracted to them, they were more likely to pay attention to their studies in English. Images played an important role in supporting learning because they were captured students' attention and encouraged them to focus on the subject at hand.

4.4.3. Pictures to assist students in memorizing vocabulary words (chart of predicted words in the survey)

The images should not be ambiguous, which only contain the meanings of the words. Using pictures was an attempt to assist students in understanding the input material clearly. Teaching with pictures played an important role in meaning comprehension. This means that the use of pictures had an impact on vocabulary learning and memorizing.

\subsubsection{To make teaching activities more interesting}

Teaching English vocabulary with pictures was a method that encourages students to be more active and interested in their English classes. Students did not get bored when 
they were in an English class. The usage of pictures could create an interesting situation and improve the effectiveness of teaching and learning activities. The preceding explanation has demonstrated that using pictures to teach English vocabulary, which was an effective method for improving students' vocabulary. As a result, English language achievement was increasing daily. It could conclude that the use of pictures in teaching English vocabulary was both necessary and effective.

A specific example was a part of lexical prediction from things, events, and pictures in the survey (question 10), which showed a surprising number of them that could give relevant answers $100 \%$ of the time. About the given picture, For example, in picture 1, more than half of those who had been thought that it was a rainbow, 30.7\% was a house, and the remaining $19.3 \%$ was the sky, tree, etc. The visuals had caught the students' interest, and they had been able to learn from them. And you associated the vocabulary with the content in each image.

\section{Conclusions}

The purpose of this article is to highlight the advantages of visual vocabulary learning for non-English major students at HUFI. As a result, vocabulary is an important part of learning a foreign language. Although it has been forgotten for decades, it became a 'hot ' topic for researchers in the 1980s. Vocabulary knowledge is vital to communicative competence, and both second/foreign language acquisition and a lack of vocabulary knowledge are barriers to learning. The use of images is one of the most convenient and cost-effective methods. The age of the student, education level, English proficiency, v.v. that can affect their learning. Teachers must be mindful of these disparities while applying instructional approaches since they might impact their students' learning. They can also provide their students with vocabulary learning strategies and allow them to encounter words repeatedly in a variety of contexts.

The given data is supplied purely for research purposes. The data collection is general, however, because the survey was only available for a brief time. The preceding statements are entirely objective. The next research will look into how to successfully teach English vocabulary at HUFI if the essential conditions are met.

\section{Patents}

Funding: This research received no external funding

Conflicts of Interest: The authors declare no conflict of interest.

\section{Appendix A}

Survey question of benefits of using illustrations( pictures) in learning English vocabulary of non-English major students at HUFI.

1. Full name:

2. Gender:
a. Male
b. Female
c. Other

3. Which year are you in?
a. Freshman
b. Sophomore
c. Junior
d. Senior

4. When did you start learning English?
a. 2-4 years old
b. 4-7 years old
c. Over 7 years old 
5. Do you like learning English?
a. Like
b. Dislike c. Exciting

6. How much time do you spend learning English?
a. $<30 \mathrm{~m}$
b. $1 \mathrm{~h}$
c. $2 \mathrm{~h}$
d. $>2 \mathrm{~h}$

7. Do you think learning vocabulary is important in learning English?
a. Yes
b. No
c. Maybe

8. What are your difficulties in learning English vocabulary?

9. Have you ever used pictures to help your learning?
a. Yes
b. No

10. Guess vocabulary through pictures

Picture 1

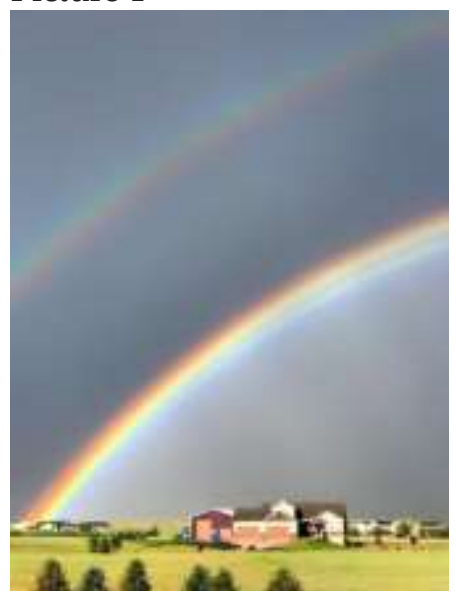

Picture 2

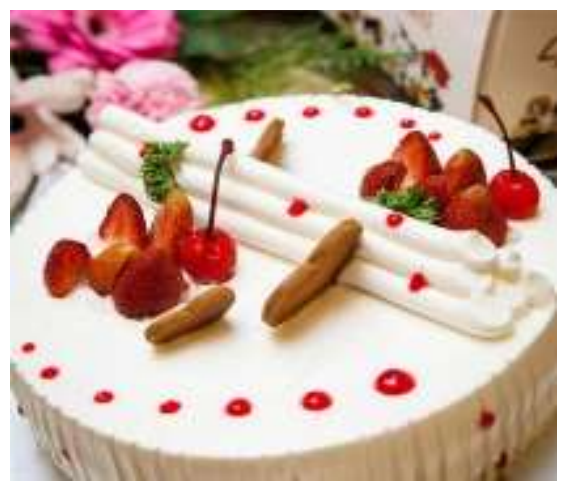

Picture 3

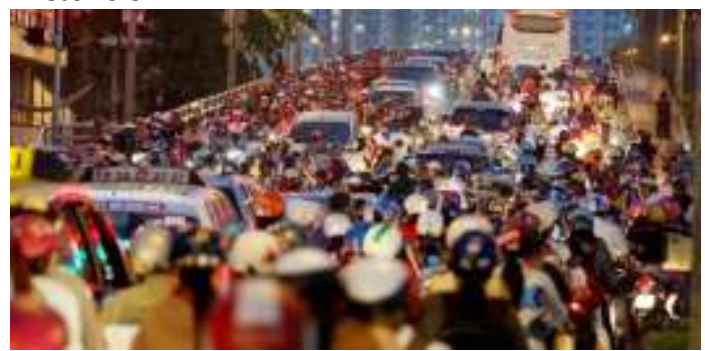




\section{References}

1. Allen, V. F. (1983). Techniques in Teaching Vocabulary. New York: Oxford University Press.

2. Alqahtani, M. (2005). The importance of vocabulary in language learning and how to be taught. International Journal of Teaching and Education, 21-34.

3. Brown, H. D. (2000). Principles of Language Learning and Teaching Fourth edition. New York: Pearson Education ESL.

4. Brown, H. D. (2004). Language Assessment: Principles and Classroom Practices (2nd Edition). New York: Pearson Education ESL.

5. Carney, R. N., \& Levin, J. R. (2002). Pictorial illustrations still improve students' learning from text. Educational Psychology Review(14), 5-26.

6. Coady, J., \& Huckin, T. (1997). Second Language Vocabulary Acquisition: A Rationale for Pedagogy. United States: Cambridge University Press.

7. DeCarrico, J. S. (2001). Vocabulary learning and teaching. In M. Celce-Murcia, Teaching English as a second or foreign language, 4th edition (pp. 285-299). Boston: Heinle ELT.

8. Domin. (2007). On application of visuals in teaching English: Selected Issues. International conference KNOWLEDGE-BASED ORGANIZATION, 356-361.

9. Gerlach, V., \& D.P.Ely. (1980). Teaching \& Media: A Systematic Approach. NJ: Prentice-Hall Incorporated.

10. Harmer, J. (1991). The Practice of English language Teaching. Essex: Longman.

11. Harmer, J. (2001). The Practice Of English Language Teaching. London: Longman.

12. Hornby, A. S. (1995). Oxford Advanced Learner's Dictionary. Oxford : Oxford University Press.

13. Houghton, H., \& Willows, D. (1987). The Psychology of Illustration. 2, 159-186.

14. Kamil, M., \& Hiebert, E. (2005). Teaching and learning vocabulary:Perspectives and persistent issues.

15. Krippendorff, K. (2004). Content analysis: An introduction to its methodology. London: SAGE Publications.

16. Lewis, M. (1993). The Lexical Approach.Language Teaching Publications. Heinle ELT.

17. McCarthy, M. (1990). Vocabulary. Oxford: Oxford University Press.

18. Phuc, T.H., Nghi, T. T. (2019). A Cognitive study of Nonlinguistic Factors Affecting the use of Prepositions by Vietnamese Native Speakers. International Journal of Applied Linguistics and English Literature, VII(1), 147-158.

19. Nghi, T. T. (2020). Applying Non-Linguistic Frameworks for Investigating the Language Transfer. International Journal of English Language and Literature Studies, 9(4), 231-243.

20. Olshansky, B. (2008). Olshansky, B. (2008). The Power of Pictures: Creating Pathways to Literacy through Art. San Francisco: Jossey-Bass. 
430 21. Oxford, R. L. (1990). Language Learning Strategies. What Every Teacher should know. Heinle ELT.

431 22. Schmitt, N. (2000). Vocabulary in language teaching. Cambridge University Press.

432 23. Son, P. N., \& Nghi, T. T. (2019). Designing Songs for Teaching and Learning English: A Literature Review. International $433 \quad$ knowledge shariing platform.

434 24. Tseng, W.-T. (2008). Toward a model of motivated vocabulary learning: A structural equation modeling approach. Language 435 Learning, 44.

436 25. Weber, R. (1990). Basic Content Analysis. London: SAGE Publications.

437 26. Wright, A., \& Tony, W. (1987). Roles of Teachers and Learners. USA: Oxford University Press. 